\title{
CONCLUSIONES A LAS V JORNADAS SOBRE CULTURA DE LOS CUIDADOS
}

$\mathrm{L}$ es confieso que no es fácil hacer unas conclusiones sobre lo que hemos compartido durante estas jornadas. Así mismo, tenemos la tendencia a hacer unas conclusiones sobre las conferencias o ponencias, dejando generalmente de lado la gran riqueza de muchas de las comunicaciones expuestas, así como de los intercambios originados en los diálogos acontecidos con ocasión de las exposiciones o en las pausas.

Las conclusiones que les exponemos vienen a ser:

- Llamadas de atención en las que, durante las exposiciones de las ponencias y comunicaciones nos recordamos dónde estamos y hacia dónde vamos.

- Profundización en los cimientos filosóficohistóricos sobre nuestra profesión.

- Reflexionar y poner de relieve la gran importancia de la cultura para dar cuidados de calidad. Sabemos que la cultura no es un ente fijo, una herencia; es un proceso que se construye en la interacción. El ser humano es un ser básicamente cultural y la cultura es una construcción del ser humano. Cada persona humana ha nacido en una comunidad de vida en la que se ha socializado.La persona interioriza unas maneras de pensar, de sentir y de actuar, a partir de esta interiorización no sólo comprende el mundo de su comunidad, sino que éste se va a convertir en su mundo. Pero al mismo tiempo esta persona va a ser un elemento constitutivo de esta cultura e inevitablemente, va a ayudar a su transmisión, su conservación y su transformación. Por tanto una cultura es dinámica y cambiante y es por ello que algunas de sus manifestaciones se conservan, otras cambian y otras desaparecen. Todo esto sucede por la interacción comunicativa que se produce en el seno de cualquier comunidad de vida... Profundizar en la riqueza de este fenómeno cultural se convierte en un pilar fundamental de los cuidados enfermeros.

- Importancia de la investigación y las publica- ciones, las cuáles nos permiten reflexionar, cimentar y avanzar en el camino de nuestra profesión.

A modo de resumen les presentamos las conclusiones según las ponencias se han ido desarrollando.

\section{Acto de apertura y conferencia inaugural}

- Necesitamos líneas de investigación para atender al ser humano desde la sencillez de lo cotidiano.

- Necesitamos dotar nuestra práctica de sensibilidad cultural en la forma de comunicar.

- La enfermería de hoy y de siempre se cimenta en la Historia cuyo punto de referencia es la hospitalidad. Todo lo que se aleje de esta hospitalidad será un engaño.

- Hospitalidad y enfermería son conceptos unívocos.

- La enfermería en sus cuidados de salud reclama la dimensión espiritual, o de los valores, entre los cuales la religión es un plus.

- La fuentes doctrinales antiguas como son la Biblia, la Odisea, la Tradición Cristiana, el Corán... recalcan, dentro de los mensajes sobre la hospitalidad, la importancia de la acogida.

- La enfermería antigua como la del futuro se sitúa en estos mismos principios, como son: acogida, atención, relación y despedida.

\section{Fenómenos migratorios y su influencia en los cuidados:}

- Los pacientes extranjeros conservan su herencia cultural durante su ingreso y viven el episodio asistencial de manera distinta en algunos casos.

- Los profesionales de enfermería son conscientes de las diferencias culturales de los pacientes extranjeros y desean adquirir habilidades para unos cuidados culturalmente competentes y diferentes.

- Es necesario integrar las teorías específicas de 
competencia cultural en unidades dentro de la formación curricular de los profesionales de enfermería.

- La competencia cultural nos aporta una forma más humana de cuidar e investigar en cuidados, además de aportar una mejora de la satisfacción y calidad percibida por el usuario ante los cuidados de enfermería.

- Las prácticas despersonalizadoras no favorecen la comprensión de las demandas particulares de los pacientes inmigrados y distorsionan la relación enfermera -paciente inmigrado.

- Si los profesionales de la gestión de enfermería comprenden las peculiaridades de los pacientes con los que trabajan, serán capaces de tomar decisiones e intervenir con una planificación sanitaria, que tome en cuenta los valores de los cuidados culturales, las creencias, las formas de vida de la gente de culturas similares y diversas, con el fin de obtener resultados beneficiosos y satisfactorios en cuanto a la calidad asistencial global percibida por el paciente.

\section{Sobre el método fenomenológico en experien- cias de vida aplicado a los cuidados de salud, resaltamos:}

- Husserl plantea una metodología consistente en una reducción o suspensión del juicio como base del procedimiento, al tiempo que emplea en sus reflexiones una serie de conceptos para explicar el método fenomenológico.

- El principio de Husserl se sitúa en el ámbito del lenguaje dotado de sentido.

- La fenomenología, como toda disciplina científica que pretende reconocer el sentido de las cosas, depende esencialmente de enseñarnos algo que todavía no conocemos, de hacernos ver lo que todavía no habíamos visto, lo que debe extraer de algún ámbito que sea en sí mismo convincente y que disponga de una justificación propia.

- Husserl insiste en: "la vuelta a las cosas mismas". Hablar de algo o estudiar algo fracturando ese algo, o lo que es peor, obviando la intencionalidad de esa acción humana, no deja de ser una negación del hombre mismo.
- Se ha reflexionado sobre los conceptos de cura y cuidados en la fenomenología de Heidegger, concluyendo que ambos son equivalentes etimológicamente.

- El concepto de cuidado tiene un gran potencial semántico que puede y debe ser rentabilizado para la vertebración de la disciplina enfermera.

\section{Historia, antropología, humanidades y revistas de enfermería:}

- El proyecto "Hiades". Revista de Historia de la Enfermería, nace como consecuencia de la toma de conciencia de la importancia que la Historia de la profesión enfermera tiene para el desarrollo de la misma.

- El proyecto HIADES pretende contribuir a mejorar la imagen que la profesión enfermera proyecta, tanto dentro como fuera de la misma, difundiendo su rico pasado

\section{Revistas: Temperamentum.}

- El ser humano se encuentra plenamente enraizado con la historia y más aún, es un ser histórico.

- La enfermera, como ser humano, es también un ser histórico en devenir, es decir, en formación y desarrollo a lo largo de su vida personal y profesional.

- En el s. XXI la enfermería tiene una gran tarea: abrirse a su propio pensamiento, levantar el edificio de su filosofía como investigadora de sí misma y del profundo misterio de la naturaleza humana

- La investigación histórica de los últimos años ha ido descubriendo un riquísimo patrimonio documental y bibliográfico guardado en archivos y bibliotecas de todo el país.

- Se hace completamente necesario un amplio programa de edición y estudio de estas fuentes escritas para que los profesionales conozcan todo el acervo cultural que la profesión enfermera encierra.

\section{Cultura de los cuidados.}

- La metodología cualitativa aplicada en cultura de los cuidados.

- La calidad del cuidado de enfermería y de la salud demandan hoy día: 
- Una interpretación humanística y

- El respeto por la integridad funcional de los seres humanos.

- La gerencia del cuidado por parte de enfermería es la consolidación de una cultura efectiva dentro de los sistemas de salud y educación, donde el acto de cuidar es una reciprocidad entre la persona o las personas que reciben la acción de cuidar y el profesional de enfermería responsable de dicho cuidado.

- Los estudios cualitativos en general hacen evidentes los componentes del cuidado, los cuales no son considerados en los estudios cuantitativos, permiten así la comprensión y la justa valoración del trabajo de cuidar del otro

- La enfermería está en una posición privilegiada para explicar a otros el mundo del enfermo, su familia y los procesos que acontecen al interior, conoce esos mundos como no lo hace otra disciplina. Metodologías cualitativas como la Teoría Fundamentada formalizan este conocimiento y con ello contribuyen a unos cuidados de enfermería culturalmente competentes y congruentes. $\mathrm{O}$ la utilización de la investigación acción como un instrumento que mejora la práctica enfermera, como una metodología que permite cambiar la práctica y mejorar la oferta de cuidados de enfermería al paciente y la familia. Favorece inscribirse dentro de un paradigma holístico el cual responde adecuadamente a las necesidades identificadas por la enfermera, el paciente y la familia.

Resumió. Luis Cibanal Juan

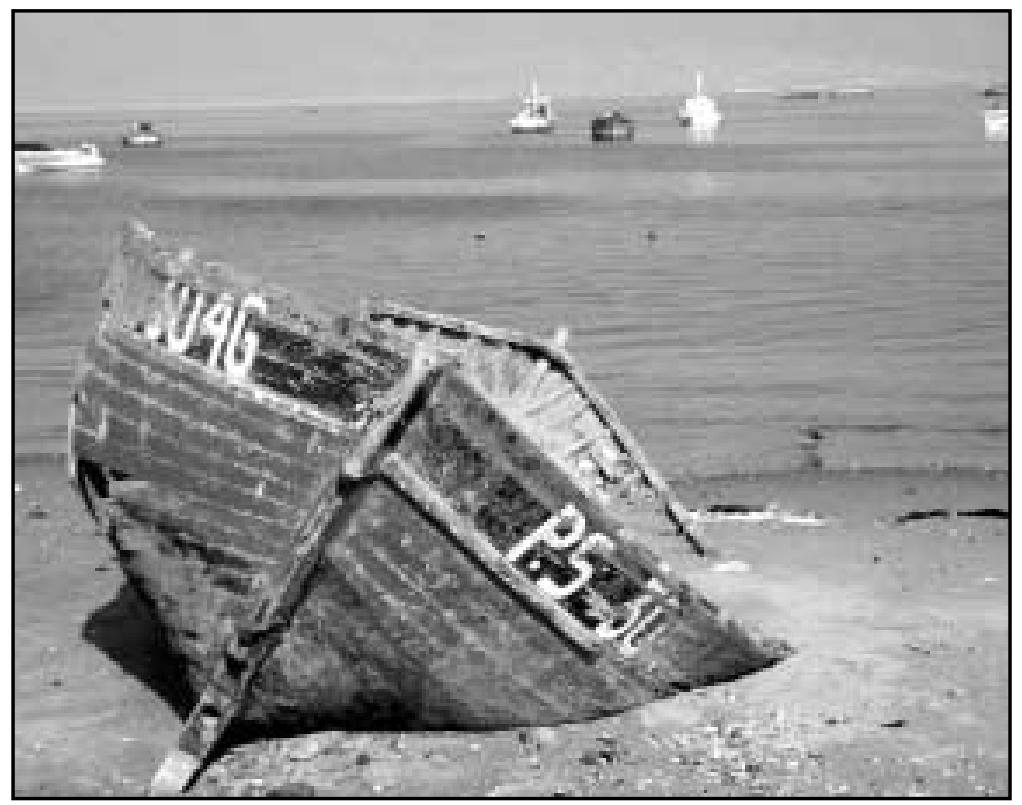

